\title{
Thermomagnetic Analysis of the Lake Matano Sediments and the Surrounding Lateritic Soils, South Sulawesi, Indonesia
}

\author{
Silvia Jannatul Fajar ${ }^{1 *}$, Gerald Tamuntuan ${ }^{2}$, Satria Bijaksana ${ }^{1}$, James Russell ${ }^{3}$ \\ ${ }^{1}$ Faculty of Mining and Petroleum Engineering, Institut Teknologi Bandung, Jalan Ganesa 10, Bandung 40132, Indonesia \\ ${ }^{2}$ Faculty of Mathematics and Natural Sciences, Sam Ratulangi University, Kampus Unsrat, Manado 95115, Indonesia \\ 2 Department of Earth, Environmental, and Planetary Sciences, Brown University, Providence 02912, USA \\ *Email: silviajannatulfajar@gmail.com
}

Submit: July 10, 2018 ; Revised: September 4, 2018; Accepted: September 10, 2018

\begin{abstract}
Thermomagnetic is one of the most commonly used measurements for determining the dominant type of magnetic mineral of samples. The measurement is separated into two distinct processes, heating and cooling. The sample susceptibility is measured for each temperature change, i.e., from room temperature to $700 \mathrm{oC}$ and vice-versa. Based on the thermomagnetic measurement results, magnetite is found to be the predominant magnetic minerals in Lake Matano sediments. The present study applied a correlation analysis technique on the results of thermomagnetic measurement of Lake Matano sediments and compared the result to that of lateritic soils to indicate whether a diagenetic process has occurred on the lake sediments.

Keywords: thermomagnetic, magnetite minerals, Lake Matano sediments, lateritic soils, correlation analysis, diagenesis
\end{abstract}

\section{INTRODUCTION}

Lake sediments are formed in a closed system and have a relatively high depositional rate [Li et al, 2006]. This makes them suitable samples by which information regarding the environmental history in the vicinity of the corresponding lake was recorded. The known carriers of this information are the magnetic minerals within the sediments. Magnetic minerals are what controls the magnetic properties of the lake sediment samples. Thermomagnetic measurement is one of the commonly used measurements for the determination of the type of dominant magnetic minerals contained in samples.

Tamuntuan et al [2015] in their study concluded that the Lake Towuti sediments (one of the members of the Malili Lake Complex) had undergone an intensive diagenetic process [Tamuntuan et al, 2015]. Thus, this study was carried out with the purpose of examining whether the Lake Matano sediments have also undergone the same process, using the results of thermomagnetic measurements (Figure 1). A correlation analysis between the results of thermomagnetic measurements on two samples could be used to assist us in seeking solutions to the problems of this study. Two different variables (the samples) would have a correlation coefficient value of 1 should they be perfectly positively

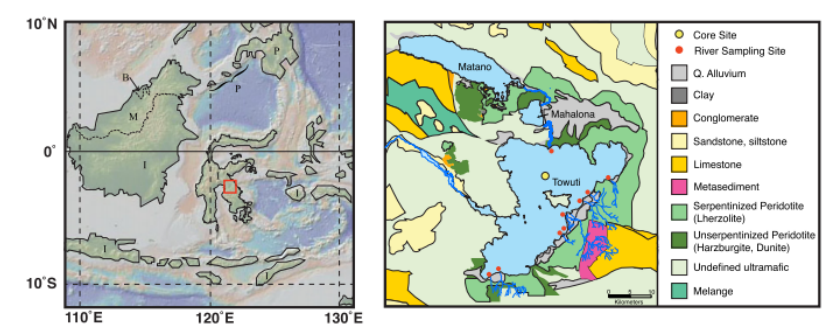

Gambar 1. Left: Indo-Pacific Warm Pool region map. Right: Geological map of Malili Lake Complex [Costa et al, 2015]

correlated, and conversely a value of -1 if they are perfectly negatively correlated. A zero-correlation coefficient indicates that the two samples are uncorrelated.

\section{METHOD}

Lake Matano, with an area extent of $164 \mathrm{~km} 2$ and a maximum depth of $590 \mathrm{~m}$ is one of the lakes within the Malili Lake Complex, South Sulawesi. It is one of the deepest lakes in Southeast Asia and is the seventh deepest lake in the world [Machbub, 1997]. Geologically, Lake Matano was formed by a graben [Crowe et al, 2008], the formation of which was triggered by the Matano Fault and has induced the creation of lineaments on the lake's rims, further causing the region bounded by the lineaments to move downwards. The magnitude of activity of the Matano Fault was predicted to be about $2 \mathrm{~cm} / \mathrm{yr}$ [Tamuntuan et al, 2010]. Areas surrounding Lake Matano is dominated by lateritic soils which host an abundance of iron oxide minerals. These soils were the results of the weathering involving ultramafic rocks [Moon et al, 2006] which originated from an ophiolite suite. Ultramafic igneous rocks have low silica content $(<45 \%)$ and possess abundant dark-colored minerals of high $\mathrm{Fe}$ and $\mathrm{Mg}$ contents [Best, 2003]. Figure 1 shows that in addition to ultramafic rocks, other lithologies such as limestone and conglomerates also comprise the rock types of this region, particularly that of the southern part of the lake.

The Lake Matano sediments core samples were acquired in 2010 by a joint effort of several international researchers under the IDLE (Indonesian Deep Lake Expedition) project. 
The sampling was performed using the Kullenberg Piston Corer in possession of The National Lacustrine Core Facility (LacCore) of the University of Minnesota, USA. The Lake Matano sediments core labeled Mat2B was the one used and analyzed in this study. The core sample had a total length of $9 \mathrm{~m}$ and was obtained at $2^{\circ} 31^{\prime} 10.52^{\prime \prime}$ South Latitude and $121^{\circ} 24^{\prime} 41.72$ " East Longitude. The core was subsequently split into two parts, the first being used to retrieve data by the U-Channel and discrete methods, while the second one was archived. Table 1 describe the samples ID as well as their depth. The lateritic soils that were utilized as the comparative samples of the Lake Matano sediment samples were obtained from an area northeast to the core sampling location.

The samples used in this study consisted of Lake Matano sediment samples (from the core Mat2B) and a lateritic soil sample. Each sample was measured for their susceptibility value using the Bartington MS2B instrument. The instrument measures susceptibility values in two frequencies, $470 \mathrm{~Hz}$ for the low-frequency susceptibility ( $\chi \mathrm{Lf}$ ) and another $4700 \mathrm{~Hz}$ for the high-frequency susceptibility $(\chi \mathrm{Hf})$. Based on the two measured different susceptibility values one usually obtains the percentage of frequencydependent susceptibility $(\% \chi \mathrm{Fd})$, which indicates the presence of the SP minerals (minerals having a less than 0.03 $\mu \mathrm{m}$ grain size). The measured susceptibility value for each sample is shown in Table 1. Subsequently, the thermomagnetic measurements were performed on each sample as well. These were conducted in two stages: heating and cooling. Each of the stages was undergone from room temperature up to $700^{\circ}$ celsius and vice-versa. The type of dominant magnetic minerals within the samples could be identified by examining the Curie temperature (TC). TC is the temperature at which magnetic minerals start to lose their magnetic properties.

The environmental history in the vicinity of Lake Matano could then be inferred through the results of thermomagnetic measurements, i.e., by matching the graph of the lateritic soil sample to that of Lake Matano sediments measured during heating. One of the common analyses used to identify the similarity between two sets of variables plotted as different graphs is a correlation technique. The correlation coefficient values are usually classified into +1 which indicates that both variables are positively correlated (proportional), -1 which indicates that both variables are negatively correlated (inversely proportional), and 0 which indicates that both variables are uncorrelated.

\section{RESULTS AND DISCUSSION}

The Curie temperature could be determined by the results of thermomagnetic measurement in the form of normalized temperature dependent susceptibility values graphs (Figure 2 and Figure 3). Mat2B 1-96, Mat2B 2-66, Mat2B 3-36, Mat2B 6-130, and lateritic soils display a Curie temperature of $580^{\circ}$ Celsius, which indicates the presence of magnetite. On the other hand, the two other samples possess a $>600^{\circ}$ Celsius Curie temperature, from which hematite or oxidized magnetite might be identified [Tamuntuan et al, 2015]. Mat2B 1-96 and Mat2B 6-130 samples demonstrate a unique characteristic, i.e., the significant increase in suscep- tibilities over a relatively short temperature range, starting at $300^{\circ}$ Celsius. This indicates that a transition from one to another mineral has occurred on these samples. According to Tamuntuan et al [2015], this condition might have been caused by the alteration from a less-magnetic mineral to a more-magnetic one due to the oxidation during the heating process. Three phase changes are possible: pyrite to magnetite [Tudryn and Tucholka, 2004], greigite to magnetite [Liu et al, 2004], or siderite to magnetite [Ortega et al, 2006].

Meanwhile, the results of thermomagnetic measurements during the cooling process of the Lake Matano sediments demonstrate an increase of susceptibility of each sample. This may have been caused by the formation or enrichment of ferrimagnetic minerals [Ao et al, 2010]. A larger jump of increasing susceptibility value can be seen on the Mat2B 6-130 sample, while the smallest one is displayed by the Mat2B 3-36 sample.

Table 2 displays the results of correlation analysis for the thermomagnetic measurements during heating for each sample. Each sample would have a +1 correlation coefficient when compared to itself. Lake Matano sediment samples (Mat2B 2-66, Mat2B 3-36, Mat2B 4-10, and Mat2B 5-34) yield a correlation coefficient of $>0.7$ when compared to the lateritic soil ones. Two other samples derived a $<0.5$ correlation coefficient, and an even negative one for the Mat2B 6-130 sample. Based on the obtained correlation values, we proposed two hypotheses regarding the possible environmental histories. First, the lateritic soils in the vicinity of Lake Matano have changed to the alteration of composition or chemical properties. Secondly, Lake Matano sediments have experienced a quite intensive diagenetic process during a certain time interval

Lake Matano sediments were sampled at different depths. Shallower sediments are associated with younger ages compared to those originating from deeper levels. It can be demonstrated that the Mat2B 1-96 sample gives a relatively small correlation with the lateritic soils (0.466), despite the sample being sampled from a depth that is closest to the lateritic soils. The correlation value increases with depth, with a peak demonstrated by the Mat2B 3-36 sample, and then decreases until it reaches a negative value for the Mat2B 6-130 sample, confirming that the samples in Zone 2 (high susceptibility in Fajar, 2015) have undergone a strong diagenetic process.

In addition to during the heating process, correlation analysis was also performed during the cooling process (Table 3. Each Lake Matano sediment sample yielded a $>0.8$ correlation coefficient value with the lateritic soils. This demonstrates that the processes of oxidation and reduction that occurred on the Lake Matano sediment and lateritic soil samples were such that they caused the susceptibility versus temperature curve to have the similar shape. This indirectly implied that the types of magnetic minerals comprising both the Lake Matano and lateritic soils are somewhat similar.

\section{CONCLUSIONS}

The result of thermomagnetic measurements has enabled identification of the type of dominant magnetic minerals to present within the Lake Matano, that is, magnetite (Fe3O4). The correlation analysis on the results of measurement dur- 
Tabel 1. Susceptibilities of Lake Matano sediment and lateritic soil samples.

\begin{tabular}{|c|c|c|c|c|}
\hline Sample Name & Depth $\mathbf{( c m})$ & $\chi \mathbf{L f}\left(10^{-8} \mathrm{~m}^{3} / \mathbf{k g}\right)$ & $\chi \mathbf{H f}\left(10^{-8} \mathrm{~m}^{3} / \mathbf{k g}\right)$ & $\mathbf{\%} \chi \mathbf{F d}$ \\
\hline Mat2B 1-96 & 28 & 139.6 & 128.1 & 8.238 \\
\hline Mat2B 2-66 & 141 & 284.7 & 256.9 & 9.765 \\
\hline Mat2B 3-36 & 257 & 460.7 & 416.4 & 9.616 \\
\hline Mat2B 4-10 & 381 & 263.1 & 239.6 & 8.932 \\
\hline Mat2B 5-34 & 541 & 126.8 & 121.1 & 4.495 \\
\hline Mat2B 6-130 & 738 & 74.9 & 73.7 & 1.602 \\
\hline Lateritic Soil & - & 6385.4 & 5755.0 & 9.87 \\
\hline
\end{tabular}
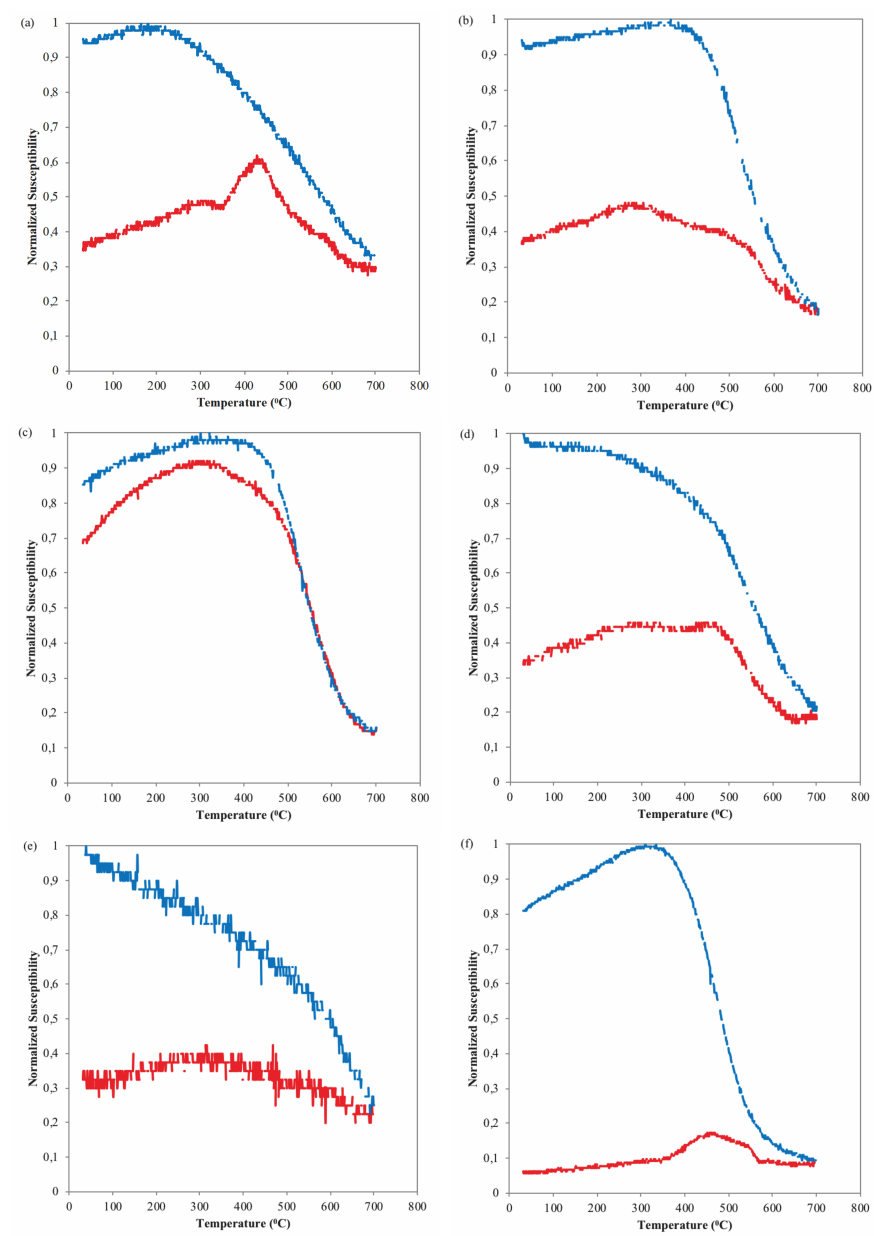

Gambar 2. Curves of the normalized magnetic susceptibility values to the change in temperature of the samples: (a) Mat2B 1-96; (b) Mat2B 2-66; (c) Mat2B 3-36; (d) Mat2B 4-10; (e) Mat2B 5-34; (f) Mat2B 6-130. (red: heating process; blue: cooling process)

Tabel 2. The correlation coefficient of the thermomagnetic measurement on the Lake Matano sediment and lateritic soil samples during heating.

\begin{tabular}{|c|c|c|c|c|c|c|c|}
\hline & Mat2B 1-96 & Mat2B 2-66 & Mat2B 3-10 & Mat2B 4-10 & Mat2B 5-34 & Mat2B 6-130 & Lateritic Soil \\
\hline Mat2B 1-96 & 1.000 & 0.715 & 0.742 & 0.830 & 0.672 & 0.652 & 0.466 \\
\hline Mat2B 2-66 & & 1.000 & 0.990 & 0.966 & 0.903 & 0.074 & 0.901 \\
\hline Mat2B 3-36 & & & 1.000 & 0.978 & 0.891 & 0.091 & 0.918 \\
\hline Mat2B 4-10 & & & 1.000 & 0.866 & 0.270 & 0.834 \\
\hline Mat2B 5-34 & & & & & 1.000 & 0.045 & 0.799 \\
\hline Mat2B 6-130 & & & & & & 1.000 & -0.274 \\
\hline Lateritic Soil & & & & & & \multicolumn{2}{c|}{1.000} \\
\hline
\end{tabular}




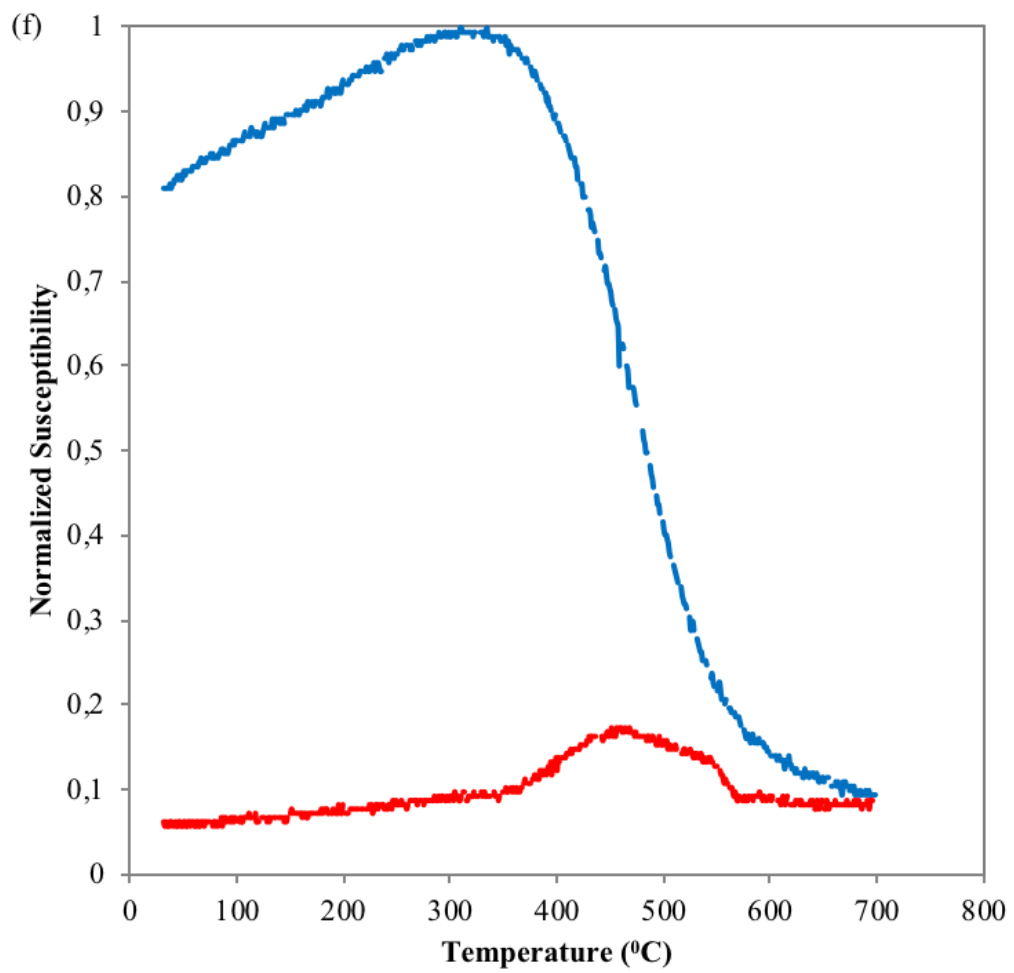

Gambar 3. Curves of the normalized magnetic susceptibility values to the change in temperature of the Lateritic soil. (red: heating process; blue: cooling process)

Tabel 3. The correlation coefficient of the thermomagnetic measurement on the Lake Matano sediment and lateritic soil samples during cooling.

\begin{tabular}{|c|c|c|c|c|c|c|c|}
\hline & Mat2B 1-96 & Mat2B 2-66 & Mat2B 3-10 & Mat2B 4-10 & Mat2B 5-34 & Mat2B 6-130 & Lateritic Soil \\
\hline Mat2B 1-96 & 1.000 & 0.941 & 0.922 & 0.989 & 0.971 & 0.954 & 0.956 \\
\hline Mat2B 2-66 & & 1.000 & 0.997 & 0.972 & 0.908 & 0.964 & 0.960 \\
\hline Mat2B 3-36 & & & 1.000 & 0.957 & 0.883 & 0.952 & 0.950 \\
\hline Mat2B 4-10 & & & 1.000 & 0.975 & 0.953 & 0.952 \\
\hline Mat2B 5-34 & & & & & 1.000 & 0.886 & 0.882 \\
\hline Mat2B 6-130 & & & & & 1.000 & 0.999 \\
\hline Lateritic Soil & & & & & \\
\hline
\end{tabular}

ing heating between the Lake Matano sediments and lateritic soil samples concluded that there had been an intensive diagenetic process at Zone 2. Correlation analysis of the results of measurements during cooling indicated that each sample contains somewhat homogeneous and similar magnetic mineral type.

\section{REFERENCES}

Ao, H and Deng, C and Dekkers, M J and Liu, Q., 2010, Magnetic Mineral Dissolution in Pleistocene Fluvio-Lacustrine Sediments, Nihewan Basin (North-China), Earth and Planetary Science Letters, 292, pp. 191-200

Best, M G., 2003, Igneous and Metamorphic Petrology. Wiley-Blackwell.

Costa, K M and Russell, J M and Vogel, H and Bijaksana, S., 2006. Hydrological Connectivity and Mixing of Lake Towuti, Indonesia in Response to Paleoclimatic Changes over the Last 60000 Years, 2015. Palaeogeography, Palaeoclimatology, Palaeoecology, 417, pp. 467-475

Crowe, S A and O'Neill, A H and Katsev, S and Hehanussa, $\mathrm{P}$ and Haffner, G D and Sundby, B and Mucci, A and Fowle, D A, 2008. The Biogeochemistry of Tropical Lakes: A Case Study from Lake Matano, Indonesia, 53, 1, pp. 319-331.

Fajar, S J, 2015,Analisis Termomagnetik pada Sedimen Danau Matano dan Tanah Laterit di Sekitarnya, Sulawesi Selatan, Indonesia, in Bahasa Indonesia with English abstract, Jakarta. Geophysical Engineering Master Thesis, Institut Teknologi Bandung

Li, Y X and Yu, Z and Kodama, K P and Moeller, R E, 2006, A 14.000-year Environmental Change History Revealed by Mineral Magnetic Data from White Lake, New Jersey, USA. Earth and Planetary Science Letters, 246, pp. 27-40

Liu, J and Zhu, R X and Li, S Q and Chang, J H., 2004. High-resolution Analysis of Early Diagenetic Effects on Magnetic Minerals in Post-Middle-Holocene Continental 
Shelf Sediments from the Korea Strait, Journal of Geophysical Research, 109, pp. 1-15

Machbub, B and Terangna, $\mathrm{N}$ and Rusmiputro, $\mathrm{S}$ and Achmad, F and Boer, L and Brahmana, S S and Prihadi, B and Setiadji, B and Sayuman, O and Margana, A., 1997, National Inventory of the Major Lakes and Reservoirs in Indonesia. PPKPL, ITB.

Moon, C J and Whateley, M E G and Evans, A M, 206, Introduction to Mineral Exploration, Blackwell Publishing, edition 2 .

Ortega, B and Caballero, M and Lozano, S and Vilaclara, G and Rodriguez, A., 2006. Rock Magnetic and Geochemical Proxies for Iron Mineral Diagenesis in a Tropical Lake: Lago Verde, Los Tuxtlas, East-Central Mexico, Earth and Planetary Science Letters, 250, 444-458

Tamuntuan, G and Bijaksana, S and Gaffar, E and Russell, J and Safiuddin, L O and Huliselan, E., (2010). The Magnetic Properties of Indonesian Lake Sediment: A Case Study of a Tectonic Lake in South Sulawesi and Maar Lakes in East Java, ITB Journal of Science, 42A, 1, pp.3148

Tamuntuan, G and Bijaksana, S and Russel, J and Fauzi, U and Maryunani, K and Aufa, N and Safiuddin, L O, 2015. Variation of Magnetic Properties in Sediment from Lake Towuti, Indonesia, and Its Paleoclimatic Significance, 420, pp. $163-172$

Tudryn, A and Tucholka, P, 2004. Magnetic Monitoring of Thermal Alteration for Natural Pyrite and Greigite, Acta Geophysica Polonica, 52, pp. 509-520 